\title{
Proteaceae endémicas del Perú
}

Blanca León ${ }^{1,2}$

${ }^{1}$ Museo de Historia Natural, Av. Arenales 1256, Aptdo. 14-0434, Lima 14, Perú

2 Plant Resources Center, University of Texas at Austin, Austin TX 78712 EE.UU.

blanca.leon@mail.utexas.edu

\section{Resumen}

La familia Proteaceae es reconocida en el Perú por presentar cinco géneros y 19 especies (Brako \& Zarucchi, 1993), todas ellas árboles y arbustos. En este trabajo reconocemos cuatro especies endémicas en dos géneros. El género Roupala es el más rico en especies. Los taxones endémicos se encuentran principalmente en la región Bosques Muy Húmedos Montanos, probablemente entre los 1000 hasta 2500 de altitud. La mayoría de las especies endémicas se conocen de muy pocas localidades y de ejemplares recolectados en el siglo XIX o a inicios del XX. Ninguna de las especies endémicas se encuentra representada dentro del Sistema Nacional de Áreas Naturales Protegidas por el Estado.

Palabras claves: Proteaceae, Roupala, Perú, endemismo, plantas endémicas.

\section{Abstract}

The Proteaceae are represented in Peru by five genera and 19 species (Brako \& Zarucchi, 1993), all trees and shrubs. Here we recognize four endemic species in two genera. Roupala is the genus with the largest number of endemic species. These endemic species are found mainly in the Very Humid Montane Forests region, probably between 1000 and $2500 \mathrm{~m}$ elevation. Most endemic species are known from a few localities, and from specimens collected in the $19^{\text {th }}$ or at the beginning of the $20^{\text {th }}$ century. None of these endemic species has been recorded in the Peruvian System of Protected Natural Areas.

Keywords: Proteaceae, Roupala, Peru, endemism, endemic plants.

\section{Euplassa isernii Cuatrec.}

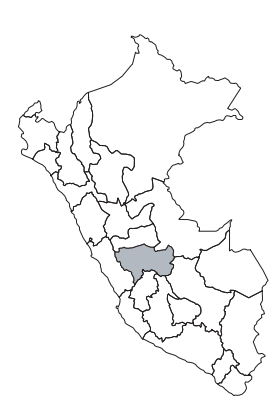

\section{DD}

Publicación: Field Mus. Nat. Hist., Bot. Ser. 13(2/2): 370. 1937.

Colección tipo: J. Isern 2283

Herbarios: F, MA.

Nombre común: Desconocido

Registro departamental: JU.

Regiones Ecológicas: Sin datos; altitud desconocida.

SINANPE: Sin registro

Herbarios peruanos: Ninguno.

Observaciones: Especies arbórea o arbustiva coocida solamente de una localidad, en el valle de Chanchamayo. Aparentemente no ha vuelto a ser recolectado desde 1863 . No se conocen las características de su hábitat, ni el rango altitudinal del mismo, aunque probablemente provenga de bosques montanos.

\section{Roupala pinnata (Ruiz \& Pav.) Diels}

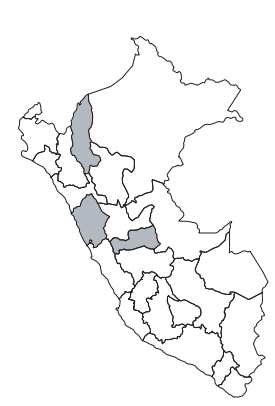

\section{EN, B1ab(iii)}

Publicación: Field Mus. Nat. Hist., Bot. Ser. 13(2/2): 374, nom.illeg. (No Lamarck, 1791.) 1937

Colección tipo: H. Ruiz \& J. Pavón s.n.

Herbarios: MA.

Nombre común: Desconocido,

Registro departamental: AM, HU, PA.

Regiones Ecológicas: BMHM, BMHP; 1200-2100 m.

SINANPE: Sin registro.

Herbarios peruanos: MOL (1).

Observaciones: Esta especie arbórea se conoce del norte y centro del país de unas pocas colecciones. El nombre de la especie en el género Roupala necesita reemplazo, pues ya fue empleado para otra especie, del este de América del Sur. Amenazas a sus poblaciones están asociados a la deforestación.

\section{Roupala sphenophyllum Diels ex Sleumer}

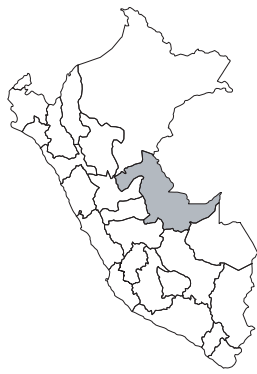

CR, B1ab(iii)

Publicación: Bot. Jahrb. Syst. 76(2): 166167. 1954.

Colección tipo: G. Tessmann 3431

Herbarios: B, G.

Nombre común: Desconocido.

Registro departamental: UC.

Regiones Ecológicas: BHA; altitud desconocida.

SINANPE: Sin registro.

Herbarios peruanos: Ninguno.

Observaciones: Este árbol pequeño se conoce de una localidad, Yarinacocha, ubicada hoy en Ucayali. Aparentemente, no ha vuelto a ser recolectada desde 1923. Amenazas en la localidad original, están asociadas a la deforestación.

\section{Roupala spicata Baehni}

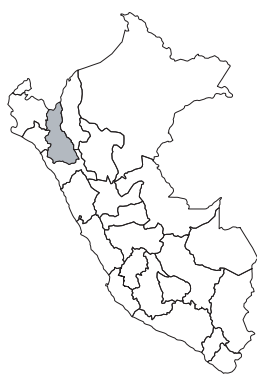

$$
\text { CR, B1ab(iii) }
$$

Publicación: Field Mus. Nat. Hist., Bot. Ser. 13(2/2): 375. 1937.

Colección tipo: A. Weberbauer 4192

Herbarios: G; MOL!.

Nombre común: Desconocido.

Registro departamental: CA.

Regiones Ecológicas: MA; $2300-2500 \mathrm{~m}$.

SINANPE: Sin registro.

Herbarios peruanos: MOL (isotipo).

Observaciones: Esta especie arbórea se conoce solamente de una localidad, en la cuenca del río Chotano. Aparentemente, no ha vuelto a ser recolectada desde 1904. Su hábitat en los matorrales y fragmentos de bosques, en las vertientes occidentales, están afectadas por la expansión de la agricultura. 